Check for updates

Cite this: RSC Adv., 2018, 8, 4731

Received 24th August 2017

Accepted 16th January 2018

DOI: $10.1039 / c 7 r a 09375 f$

rsc.li/rsc-advances

\section{Effect of sodium alginate on the stability of natural soybean oil body emulsions}

\author{
Chunxia Su, ${ }^{a}$ Younan Feng, ${ }^{\text {a }}$ Jing Ye, ${ }^{a}$ Yuemei Zhang, ${ }^{a}$ Zhiming Gao, ${ }^{\text {ab }}$ Meng Zhao, ${ }^{\text {ab }}$ \\ Nan Yang, (D) *ab Katsuyoshi Nishinari ${ }^{a}$ and Yapeng Fang (D)*ab
}

In this work, the influence of an anionic polysaccharide, sodium alginate (ALG), on the stability of soybean oil body (OB) emulsions under different environmental conditions, including $\mathrm{NaCl}, \mathrm{pH}$ and freeze-thaw cycling, was studied by analyzing the particle electric charge, particle size and distribution, and using optical and fluorescence microscopy. Sodium dodecyl sulfate-polyacrylamide gel electrophoresis (SDSPAGE) showed that the proteins on the surface of oil bodies were mainly oleosins. It was found that ALG can be adsorbed to the surface of oil bodies by strong electrostatic interactions at $\mathrm{pH} 4.5$ and the optimal concentration of ALG was 0.35 wt\% for 1 wt\% OB emulsions. At pH 4-8, ALG-coated OB emulsions were more stable than uncoated $O B$ emulsions with smaller particle size and more uniform size distribution due to the interaction between OB and ALG. The ALG-coated OB emulsions were also all stable against $\mathrm{NaCl}$ within the concentration range of $0-250 \mathrm{mM}$ at $\mathrm{pH} 7$ while uncoated $\mathrm{OB}$ emulsions aggregated gradually with the increase of $\mathrm{NaCl}$ concentration. For $\mathrm{OB}$ emulsions with higher concentration of 10-40 wt\% which are frequently used in the food industry, the minimal concentration of ALG required to make stable emulsions was found to be $0.5-1 \mathrm{wt} \%$, correspondingly. Coating oil bodies with ALG also significantly improved the stability of natural oil body emulsions against freezethaw cycling, which is of great significance to the further development of natural oil body-based products in food industry.

\section{Introduction}

Oil bodies are micron- or submicron-sized organelles found mainly in plant seeds, and nuts, as well as other parts such as leaves, bulbs and fruits. ${ }^{\mathbf{1 , 2}}$ They are natural oil droplets with an internal core of liquid triglycerides, covered with an embedded monolayer membrane of phospholipids and oil body proteins (mainly oleosins, caleosins and steroleosins).$^{3-6}$ The oil bodies serve as the food energy reserves for germination and plant growth and the coating of phospholipids and amphiphilic proteins provides the oil bodies with physical and chemical stability against environmental perturbation, such as moisture, temperature fluctuations and the presence of oxidative reagents. ${ }^{\mathbf{4}, \mathbf{6}, 7}$ Oil bodies have recently gained much attention for their potential applications in foods, cosmetics, and pharmaceuticals, due to their nutritive value and in particular their natural emulsification properties. ${ }^{8-10}$ Soybean oil bodies could be utilized in food products as ingredients in place of

${ }^{a}$ Glyn O. Phillips Hydrocolloid Research Centre, Food Hydrocolloid International Science and Technology Cooperation Base of Hubei Province, Department of Bioengineering and Food Science, Hubei University of Technology, Wuhan 430068, China. E-mail: nanyang27@gmail.com; fangypphrc@163.com; Fax: +86-2788015996; Tel: +86-27-88015996

${ }^{b}$ Hubei Collaborative Innovation Centre for Industrial Fermentation, Hubei University of Technology, Wuhan 430068, China emulsified soybean oil, for example, in dressings, sauces, dips, beverages, and desserts, with the advantage that neither emulsifiers nor homogenization procedures are required. However, in the course of food processing, emulsions are often affected by the addition of mineral elements, thermal cycling, and acid adjustment, which may reduce the stability of the emulsion system, via flocculation, aggregation, creaming, or even demulsification. Iwanaga et al. previously investigated the influence of $\mathrm{pH}$, ionic strength, and thermal processing on the properties and stability of oil bodies extracted from soybeans. ${ }^{11}$ They showed that oil bodies were stable to aggregation and creaming at low $(\mathrm{pH}=2)$ and high $(\mathrm{pH} \geqq 6) \mathrm{pH}$ values but were unstable at intermediate values $(3 \leqq \mathrm{pH} \leqq 5)$, which was attributed to their relatively low $\zeta$-potential. And the oil bodies were stable to aggregation and creaming at relatively low salt concentrations $(\mathrm{NaCl}<50 \mathrm{mM}, \mathrm{pH} 7)$ but were unstable at higher values as a result of electrostatic screening effects. The relatively poor physical stability of oil bodies to aggregation severely limits the range of products in which they could be utilized in the food, health care, and pharmaceutical industries. Therefore, the successful utilization of soybean oil bodies in food products requires a thorough understanding of their functional performance under different environmental conditions. 
Researchers recently attempted to use polysaccharides to improve the stability of emulsion droplets by modifying the interfacial composition of droplets with polysaccharides. Benichou et al. have reported that the molecules of xanthan may interact with those of whey protein and produce hybrids conjugates with improved surface activity. ${ }^{12}$ Wang et al. reported that the gum arabic adsorbed at soybean protein concentrate can stabilize oil-in-water interface at different $\mathrm{NaCl}$ concentrations and high temperature. ${ }^{13}$ It was also reported that gum arabic can decrease interfacial tension via attractive electrostatic interactions with $\beta$-lactoglobulin. ${ }^{\mathbf{1 4}}$ It has been proved that the method is feasible to improve the stability of emulsion droplets in environmental perturbation, which may be attributed to the effect of electrostatic deposition and steric repulsion of polysaccharides between emulsion droplets.

Sodium alginate (ALG) is a linear anionic natural polysaccharide present in brown algae marine organisms. ALG is a biodegradable polymer used extensively in food, medical and pharmaceutical industries due to thickening, emulsifying and gelling properties. ${ }^{15,16}$ ALG also is related to reduction of serum cholesterol, triglyceride and blood glucose, and thus can prevent hypertension, diabetes, obesity and other life-style related diseases. It is composed of glucosidic bonds polymerized by $1,4(\alpha$ or $\beta$ )glycosylation of an $\alpha$-L-guluronic acid (G) and a $\beta$-D-mannuronate acid $(\mathrm{M}) \cdot{ }^{17} \mathrm{G}$ and $\mathrm{M}$ monomers are arranged alternately to form three different structural segments: a continuously distributed $\mathbf{M}$-block region (-M-M-M-M-), a continuously distributed G-block region $(-\mathrm{G}-\mathrm{G}-\mathrm{G}-\mathrm{G}-)$, and two monomer-alternating GM block region (-M-G-M-G-). And there are continuously distributed negatively charged carboxyl groups on the molecular chain of ALG. Previous studies found that ALG was the most effective at creating highly charged interfacial membrane around droplets because of its highly charged linear structure, thereby reducing the flocculation of emulsion droplets through the electrostatic repulsion. ${ }^{18}$ Fioramonti et al. found that ALG can interact with whey protein isolate (WPI) at $\mathrm{pH}$ values below the isoelectric point (IEP) of WPI, to improve the stability of WPI stabilized oil-in-water emulsions. ${ }^{18,19}$ However, no work has been reported about the effect of ALG on the stability of soybean oil bodies.

Although some researchers have reported the similar work about using polysaccharides to stabilize oil bodies before, there are still many limits, etc. the stability of oil body emulsions stabilized by $\mathrm{t}$-carrageenan in freeze-thaw cycle was partly unsatisfactory, and carrageenan couldn't disperse the oil bodies very well at $\mathrm{pH} 7 .^{20}$ Besides, a high concentration of oil phase is usually used in the real food emulsion products, which was not studied and presented in previous works. In this study, we extracted soybean oil bodies by aqueous method and then coated them with ALG. We investigated the interactions between ALG and oil bodies, and the impact of ALG on the physicochemical stability of soybean oil body (OB) emulsions over a range of $\mathrm{pH}$ values (3-8), ionic strength $(0-250 \mathrm{mM} \mathrm{NaCl})$, and freeze-thaw cycling $\left(-20{ }^{\circ} \mathrm{C}, 22 \mathrm{~h} / 40{ }^{\circ} \mathrm{C}, 2 \mathrm{~h}\right)$. The concentration upper limit of oil body emulsions which can be stabilized by ALG was also studied. This study aims to improve the stability of the OB emulsions and thus soybean oil bodies by applying ALG, and to further broaden the scope of application of soybean oil bodies in food industry.

\section{Materials and methods}

\subsection{Materials}

Soybeans were purchased from the local food company, Yi hai Co., Ltd. ALG were kindly provided by FMC BioPolymer (Norway). The composition and properties of the ALG were as follows: molecular weight $\left(M_{\mathrm{w}}\right), 111 \mathrm{~kg} \mathrm{~mol}^{-1}$; polydispersity index: $1.44 ; \alpha$-L-guluronate: $74.1 \%$; $\beta$-D-mannuronate: $25.9 \%$. The fluorescent dyes of Nile red and isothiocyanate rhodamine B (RBITC) were purchased from Sigma Chemical Co. (St. Louis, MO, USA). Other chemicals were of analytical grade and purchased from Sinopharm Chemical Reagent Co. Ltd. (China). Ultra-pure water (Direct Q3, Merck Millipore, USA) was used to prepare all solutions and emulsions.

\subsection{Extraction of soybean oil bodies}

Oil bodies were extracted from a homogenate of mature soybeans according to the method of $\mathrm{Wu}$ et al. with slight modifications. ${ }^{21}$ Soybeans were soaked in distilled water $(1: 5$, $\mathrm{w} / \mathrm{v}$ ) for $18-20 \mathrm{~h}$ at $4-6{ }^{\circ} \mathrm{C}$. The soaked soybeans were then blended in grinding buffer solution (50 mM Tris- $\mathrm{HCl}, \mathrm{pH} 7.5$ ) containing $0.4 \mathrm{M}$ sucrose and $0.5 \mathrm{M} \mathrm{NaCl}$ for $180 \mathrm{~s}$ by a commercial food processor (KS-520, Guangzhou City Electric Appliance Co., Ltd., China) to obtain a homogenate of soybeans. The homogenate was filtered through three layers of cheesecloth to remove the bean dregs, and the filtrate was centrifuged at $10000 \times g, 4{ }^{\circ} \mathrm{C}$ for $30 \mathrm{~min}$ (Heraeus Multifuge X1/X1R, Thermo Fisher Scientific, USA). The upper creamy layer of the centrifugate which contained the crude oil bodies, were collected with a spoon and re-dispersed in the grinding buffer solution and centrifuged again as above. Then the collected product was dispersed in $8 \mathrm{M}$ urea solution $(1: 5, \mathrm{w} / \mathrm{v})$ at $22 \pm$ $2{ }^{\circ} \mathrm{C}$ with magnetic stirring for $1 \mathrm{~h}$. The mixture was then washed with the buffer solution again (50 mM Tris-HCl buffer, pH 7.5) for another three times. The composition of the final oil body creams was determined according to AOAC method. ${ }^{22}$ It was found that their moisture is $53.6 \pm 2.3 \mathrm{wt} \%$, fat content is $29.4 \pm 1.0 \mathrm{wt} \%$ (wet weight basis, hereafter wb), and protein content is $3.0 \pm 0.2 \mathrm{wt} \%$ (wb).

\subsection{Protein characterization by electrophoresis}

The composition of proteins on the surface of the extracted oil bodies was determined by sodium dodecyl sulfate polyacrylamide gel electrophoresis (SDS-PAGE). ${ }^{23}$ Sample preparation: soybean oil bodies were dispersed in buffer A (500 mM Tris-HCl, pH 6.8) with a volume ratio of $1: 7$, and magnetically stirred to obtain oil body suspensions. After mixing with SDS buffer (500 mM Tris-HCl, $1 \mathrm{mg} \mathrm{ml}^{-1}$ glycerol, $2.20 \%$ SDS (w/v), $\mathrm{pH}$ 6.8) with a volume ratio of $1: 1$, suspensions were vortexed for $2 \mathrm{~min}$ at $22 \pm 2{ }^{\circ} \mathrm{C}$ and diluted with buffer B (1: $0.815, \mathrm{v} / \mathrm{v}$, $500 \mathrm{mM}$ Tris- $\mathrm{HCl}, 1 \mathrm{mg} \mathrm{ml}^{-1}$ glycerol, $\mathrm{pH}$ 6.8) to a protein concentration of $2 \mathrm{mg} \mathrm{ml}^{-1}$. And then one volume of an electrophoresis sample buffer (125 mM Tris-HCl, 1\% SDS (w/v), 
$20 \%(\mathrm{v} / \mathrm{v})$ glycerol and $2 \%(\mathrm{v} / \mathrm{v})$ 2-mercaptoethanol, $0.025 \%$ bromophenol blue (w/v)) was added. After boiled for $5 \mathrm{~min}$ and centrifuged at $10000 \times g$ for $10 \mathrm{~min}$, the subnatant containing the solubilized proteins was removed with the aid of a syringe and analyzed by SDS-PAGE. ${ }^{24}$ The concentrations of the stacking and separating gels were $4.5 \mathrm{wt} \%$ and $12.5 \mathrm{wt} \%$, respectively. The samples were electrophoresed at a constant current of 18 $\mathrm{mA}$ until all samples entered into the stacking gel and then at a constant voltage of $36 \mathrm{~mA}$ until the end. After electrophoresis, the gel was stained with $0.025 \%$ (w/v) Coomassie blue G-250 in $10 \%(\mathrm{v} / \mathrm{v})$ acetic acid for $2 \mathrm{~h}$, and destained by acetic acid solution with a high methanol content. The ratio of methanol, acetic acid and deionized water was $3: 1: 6(\mathrm{v} / \mathrm{v} / \mathrm{v})$.

\subsection{Emulsion preparation}

The oil body (OB) emulsions were prepared by dispersing the oil bodies into sodium phosphate buffer solution (50 mM, pH 7) and then sonicated for $3 \mathrm{~min}$ (frequency, $20 \mathrm{kHz}$; amplitude, $40 \%$; duty cycle, $1 \mathrm{~s}$ ) using a high intensity ultrasonic probe device (VCX800, 53 Church Hill Rd. Newtown, CT, USA).

In order to make the ALG-coated OB emulsions, first ALG solution ( $\mathrm{pH} 7$ ) was prepared by dispersing weighed amounts of the powdered material into sodium phosphate buffer solution (50 mM, pH 7) and mixed completely using a roller (SRT-202, Jiangsu Haimen Lindberg Instrument Manufacturing Co Ltd., China) for $24 \mathrm{~h}$. Then the $\mathrm{OB}$ emulsions were diluted with different ratios of sodium phosphate buffer (50 mM, pH 7) and ALG solutions to make samples with the same oil body concentration and different ALG concentrations. The mixture was magnetically stirred for $2 \mathrm{~h}$, and adjusted to $\mathrm{pH} 4.5$ with $1 \mathrm{M}$ $\mathrm{HCl}$ to trigger ALG adsorption, and then stirring for another $30 \mathrm{~min}$. The samples prepared in this way were stored at $22 \pm$ $2{ }^{\circ} \mathrm{C}$ for $24 \mathrm{~h}$ before being analyzed. The concentration of oil bodies in the OB emulsions in this paper was reported on a wet weight basis (wb).

\subsection{Particle size analysis}

Droplet size and size distribution of pure OB emulsions and OB emulsions with ALG was determined with the aid of a laser light scattering instrument (Malvern Mastersizer 2000, UK). Measurements were performed at $22 \pm 2{ }^{\circ} \mathrm{C}$ following sample dilution with deionized water to an oil content of approximately $0.006 \%$. The refractive index of dispersed phase and continuous phase was 1.08 and 1.33 , respectively. Measurements are reported as the volume-weighted mean particle diameter $d_{43}$.

\section{$2.6 \zeta$-Potential measurements}

The electric charge ( $\zeta$-potential) of the particles in the emulsions was calculated by measuring the electrophoretic mobility of the droplets using a capillary electrophoresis cell (Zetasizer Nano ZS series, Malvern Instruments, Worcestershire, UK). Oil bodies were diluted to an oil content of approximately $0.005 \mathrm{wt} \%$ using a deionized water to avoid multiple scattering effects.

\subsection{Structure observation}

In order to characterize the microscopic structure of the emulsions, an optical microscope (Nikon YS100) and a CCD camera (HV2001UC) with an image particle size analyzer (BT-1600, Dandong Bettersize Instrument Ltd., China) were employed. A small drop of each emulsion sample was placed on a slide and covered with a microscope slip. Images were taken at a magnification of 10 times.

\subsection{Location of ALG in oil body emulsion}

In order to determine the interaction of ALG with oil bodies in the emulsion, RBITC was used to label ALG, and Nile red was used to label the oil bodies.

The oil body suspensions were mixed with Nile red solution (20 $\mu \mathrm{l}$ of a $0.2 \mathrm{wt} \%$ solution per $\mathrm{ml}$ sample), magnetically stirred overnight.

The well dissolved ALG solution ( $2 \mathrm{wt} \%$ ) was adjusted to $\mathrm{pH}$ 8.0 by $\mathrm{NaOH}(1 \mathrm{M})$. RBITC solution with a concentration of $1 \mathrm{mg}$ $\mathrm{ml}^{-1}$ dissolved in DMSO was added to the ALG polymer solution and stirred for $1 \mathrm{~h}$ at $40{ }^{\circ} \mathrm{C}$. The reaction of ALG and RBITC was stopped by adding $\mathrm{NH}_{4} \mathrm{Cl}^{25}$ The final solutions were dialyzed (MW 8000-10 000 spectra) against distilled water with the dialysis medium changed every $12 \mathrm{~h}$, until the deionized water was colorless and then freeze-dried. Then the dyed ALG was used to coat the oil bodies as described in Section 2.3.

Uncoated ( $1 \mathrm{wt} \%$ oil bodies, $0 \mathrm{wt} \%$ ALG) and coated ( $1 \mathrm{wt} \%$ oil bodies, $0.35 \mathrm{wt} \%$ ALG) OB emulsions were characterized by fluorescence microscopy at $22 \pm 2{ }^{\circ} \mathrm{C}$ using a fluorescence microscope (IX 73, Olympus, Japan). A drop of the stained solution was placed on a microscope slide. Images were first captured in bright field, then adjusted to the fluorescence mode with excitation/emission wavelengths of 488/538 $\mathrm{nm}$ for Nile red and 543/572 $\mathrm{nm}$ for RBITC, respectively. All the images were taken with $40 \times$ lens.

\subsection{Influence of $\mathrm{pH}$, ionic strength and freeze-thaw cycling}

The influence of $\mathrm{pH}$ and ionic strength on the properties of uncoated and ALG-coated OB emulsions was examined. The final as-prepared uncoated ( $1 \mathrm{wt} \%$ oil bodies, $0 \mathrm{wt} \% \mathrm{ALG}$ ) and coated ( $1 \mathrm{wt} \%$ oil bodies, $0.35 \mathrm{wt} \%$ ALG) OB emulsions as introduced in Section 2.4 were used. After $24 \mathrm{~h}$ of storage at $22 \pm$ $2{ }^{\circ} \mathrm{C}$, the emulsions were adjusted back to $\mathrm{pH} 7.0$ with $1 \mathrm{M}$ $\mathrm{NaOH}$, then $\mathrm{NaCl}(0-250 \mathrm{mM})$ was added to the emulsions. And after $24 \mathrm{~h}$ of storage at $22 \pm 2{ }^{\circ} \mathrm{C}$, the emulsions were adjusted to $\mathrm{pH} 3,4,5,6,7$ and 8 by the addition of $1 \mathrm{M} \mathrm{HCl}$ or $1 \mathrm{M} \mathrm{NaOH}$. The $\mathrm{OB}$ emulsions were then stored at $22 \pm 2{ }^{\circ} \mathrm{C}$ for $24 \mathrm{~h}$ prior to $\zeta$-potential, particle size and microscopic structure characterization and creaming stability analysis (visual observation) after 7 days storage.

The influence of repeated freeze-thaw cycling on the properties and stability of uncoated ( $1 \mathrm{wt} \%$ oil bodies, $0 \mathrm{wt} \%$ ALG) and coated ( $1 \mathrm{wt} \%$ oil bodies, $0.35 \mathrm{wt} \%$ ALG) OB emulsions at pH 7 was finally examined. The as-prepared uncoated and coated OB emulsions (10 g) were transferred into a transparent glass bottle with lid, and were incubated in a $-20^{\circ} \mathrm{C}$ freezer for 
$22 \mathrm{~h}$. After incubation, the emulsion samples were thawed by incubating them in a water bath at $40{ }^{\circ} \mathrm{C}$ for $2 \mathrm{~h}$. This freezethaw cycle was repeated up to three times, and its influence on the OB emulsion properties was observed after each cycle.

\subsection{Statistical analysis}

All the measurements were performed at least twice using freshly prepared samples. Average and standard deviations were calculated from these duplicate measurements. Microsoft Excel 2007 and Microsoft Word 2007 software were used for data processing and to create charts.

\section{Results and discussion}

\subsection{Protein compositions of the extracted oil bodies}

Fig. 1 shows the SDS-PAGE profile of the protein molecular masses in soybean oil bodies. Proteins in crude soybean oil bodies without wash (Lane 1, Fig. 1) include not only the important component of soybean oleosin proteins $(24,18,17$ $\mathrm{kDa})$, but also include $\beta$-conglycinin $\left(\alpha, \alpha^{\prime}\right.$, and $\left.\beta\right)$, soybean globulin (acidic and basic subunits) and some storage proteins (34 kDa). ${ }^{26-28}$ The proteins with a molecular weight of $17 \mathrm{kDa}, 18$ $\mathrm{kDa}$ and $24 \mathrm{kDa}$ are the soybean oleosin proteins, while the protein with a molecular weight of $34 \mathrm{kDa}$ is present in the vacuoles of the plant seed storage protein because it can be tightly integrated with the soybean oil body and is initially considered to be a soybean oil body protein. ${ }^{27,28}$ After the soybean oil bodies were washed with Tris-HCl buffer solution, background proteins were partially removed ( $\beta$-conglycinin, glycinin, etc.) (Lane 2, Fig. 1). And then, after washed with urea solution, only four proteins with molecular masses of 17, 18, 24, and $34 \mathrm{kDa}$ remained in soybean oil bodies (Lane 3-5, Fig. 1). Therefore, although the extraction method of soybean oil bodies could not remove the protein of molecular mass $34 \mathrm{kDa}$, it removed much of the background proteins ( $\beta$-conglycinin, glycinin, etc.).

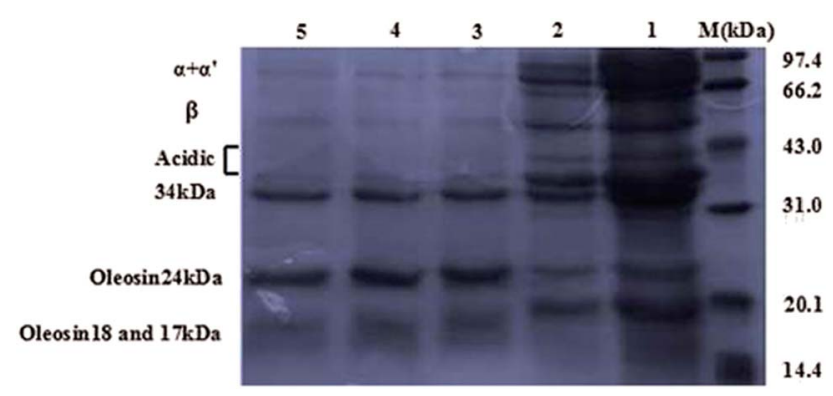

Fig. 1 SDS-PAGE profile of proteins in soybean oil bodies extracted by aqueous extraction. Lane $M$, relative molecular mass markers; Lane 1 proteins extracted from crude soybean oil bodies without wash; Lane 2 , proteins (mainly oleosins) in soybean oil bodies washed once with buffer solution; Lane 3-5, protein (oleosins) in soybean oil bodies after treatment with urea and washed 1-3 times with buffer solutions, respectively.

\subsection{Influence of ALG on oil body emulsion properties}

The interaction between the ALG and the oil bodies was studied and the optimal concentration of ALG to produce stable ALGcoated $\mathrm{OB}$ emulsions was determined by measuring the electric charge (Fig. 2a and b), mean particle diameter (Fig. 2c) and microscopic structure (Fig. 2d) of $1 \mathrm{wt} \%$ OB emulsions containing ALG with different concentrations (0-1.0 wt\%).

The $\zeta$-potential of pure ALG solution and oil body emulsions as a function of $\mathrm{pH}$ is displayed in Fig. 2a. When the $\mathrm{pH}$ changed from 8 to 3 , the $\zeta$-potential of ALG solution was always negative, but the $\zeta$-potential of the $\mathrm{OB}$ emulsions increased from $-35.3 \mathrm{mV}$ to $25.5 \mathrm{mV}$, with the point of zero charge being around $\mathrm{pH} 5.1$ (the isoelectric point). These results were consistent with the properties of protein stabilized oil/water emulsions. $^{29,30}$ For the OB emulsions, oleosin proteins and other proteins (such as storage proteins) remained around the oil bodies after the aqueous extraction procedure. Other studies have reported that the isoelectric point of oil bodies extracted from various plant sources was around $\mathrm{pH} 5-6,{ }^{31}$ similar to the isoelectric point of the soybean oil body measured in this study. The soybean OB emulsions were highly unstable near the isoelectric point, especially at the low $\mathrm{pH}$ values.

As shown in Fig. $2 \mathrm{~b}$, the $\zeta$-potential of the uncoated oil bodies was around $+4.74 \mathrm{mV}$ at $\mathrm{pH} 4.5$, where the $\mathrm{pH}$ of the oil bodies was little below their isoelectric point. Measurements of the mean particle diameter, and microscopic structure of the OB emulsions showed that they were highly unstable to aggregation at this $\mathrm{pH}$ value (Fig. $2 \mathrm{c}$ and $\mathrm{d}(0 \mathrm{wt} \% \mathrm{ALG})$ ). This aggregation is due to the fact that the $\zeta$-potential of the oil bodies was relatively small, and hence the electrostatic repulsion between them was insufficient to overcome the various attractive interactions, e.g., van der Waals and hydrophobic interactions. $^{32}$ Therefore, we utilized ALG to interact electrostatically with oil bodies at low $\mathrm{pH}$ values, e.g., $\mathrm{pH} 4.5$, in order to improve the stability of the OB emulsions.

As shown in Fig. 2b, with the addition of ALG, the electric charge of the $\mathrm{OB}$ emulsions at $\mathrm{pH} 4.5$ changed from positive to negative. The negative charge of the oil bodies reached a relatively constant value of $-(46 \pm 3) \mathrm{mV}$ when the ALG concentration was above $0.25 \mathrm{wt} \%$. These results indicate that anionic ALG molecules neutralized the positive charge on the surface of the oil bodies and eventually became saturated with ALG.

When ALG concentrations increases from $0.075 \mathrm{wt} \%$ to $0.225 \mathrm{wt} \%$, the mean particle diameter of OB emulsions is much reduced (Fig. 2c), although the microscopic structure images show that there is still a certain degree of aggregation (Fig. 2d). This type of aggregation may be attributed to the relatively low $\zeta$-potential and weak electrostatic repulsion of the oil bodies, as well as the linking together of the oil bodies by inadequate anionic ALG molecules (bridging flocculation) that occurs when the ALG concentration is below saturation coverage. ${ }^{33}$ At ALG concentrations from $0.25 \mathrm{wt} \%$ to $0.35 \mathrm{wt} \%$, the particle diameter of $\mathrm{OB}$ emulsions were reduced (Fig. 2c), and no obvious aggregation phenomenon was observed (Fig. 2d). At ALG concentrations of $0.35 \mathrm{wt} \%$, the emulsion was best dispersed with the smallest mean particle diameter. The good dispersion 
(a)
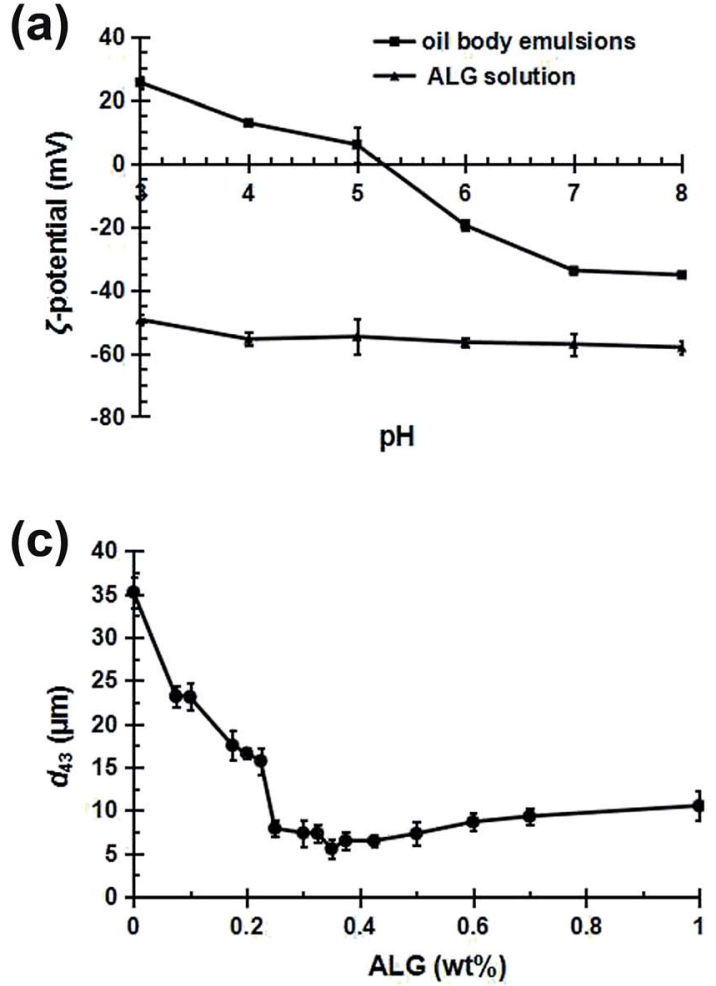

(b)

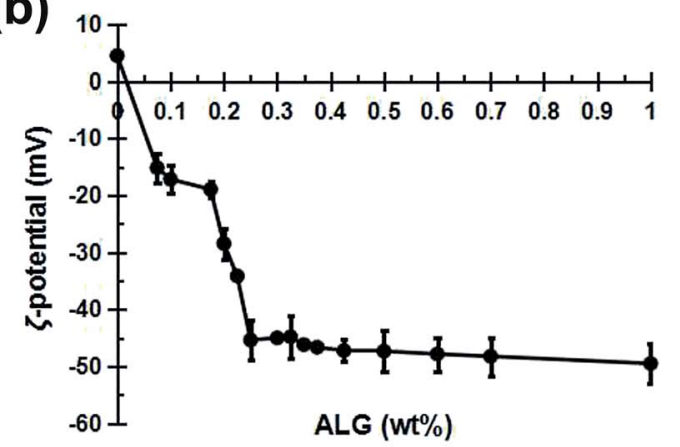

(d)

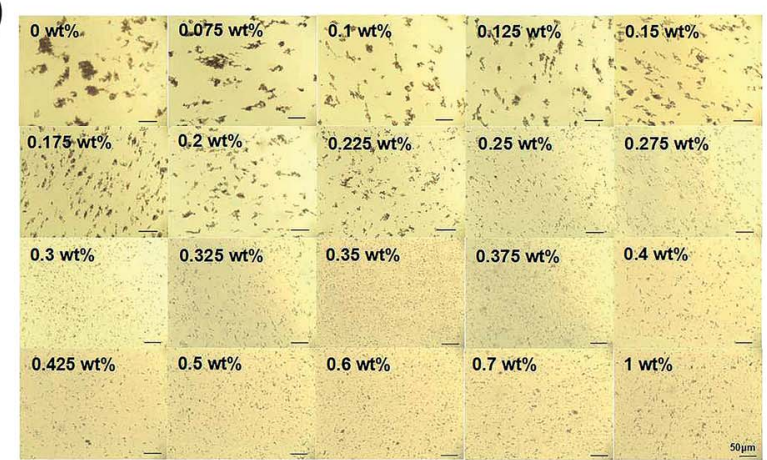

Fig. 2 The $\zeta$-potential of pure OB emulsions and pure ALG solution (a); $\zeta$-potential (b), mean particle diameter $\left(d_{43}\right)$ (c) and the microscopic structure (d) of OB emulsions each with $1.0 \mathrm{wt} \%$ oil bodies and different concentrations of ALG. The continuous phase of the emulsions is $50 \mathrm{mM}$ sodium phosphate and $\mathrm{pH}$ is 4.5 .

of the $\mathrm{OB}$ emulsions can be attributed to the ability of the ALG molecules to completely cover the oil body surfaces and form a relatively thick electrically charged coating. The adsorption process of ALG to oil bodies was schematically indicated in Fig. 3. ALG coating increases the electrostatic and steric repulsion between the oil bodies, as well as decreases the van der Waals attraction, thereby increasing their stability to aggregation. ${ }^{32}$ When the concentration of ALG exceeds $0.35 \mathrm{wt} \%$, the mean particle diameter increased again with the increase of ALG concentration (Fig. 2c). The same results can be seen from the microscopic structure, and aggregates were formed
(Fig. 2d). The decrease in stability of the OB emulsions at high ALG concentrations can be attributed to depletion flocculation induced by the high levels of non-adsorbed ALG in the continuous phase. ${ }^{33,34}$ Consequently, we used ALG concentration of $0.35 \mathrm{wt} \%$ to prepare ALG-coated oil bodies for the subsequent stability studies.

\subsection{Location of ALG in oil body emulsion}

Fluorescent micrographs of uncoated oil bodies $(1 \mathrm{wt} \%$ oil bodies, $0 \mathrm{wt} \%$ ALG) $\left(\mathrm{a}_{1}, \mathrm{~b}_{1}\right.$ and $\left.\mathrm{c}_{1}\right)$ and coated oil bodies $(1 \mathrm{wt} \%$ oil bodies, $0.35 \mathrm{wt} \%$ ALG $)\left(\mathrm{a}_{2}, \mathrm{~b}_{2}\right.$ and $\left.\mathrm{c}_{2}\right)$ are shown in Fig. 4 . For

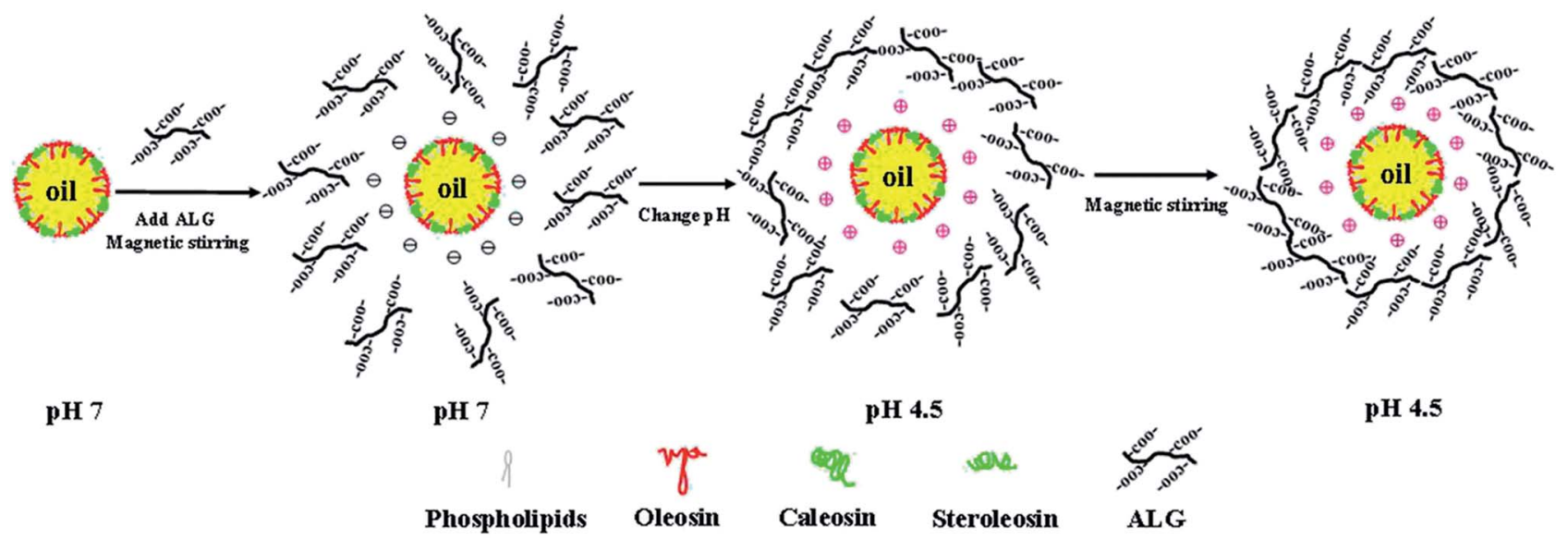

Fig. 3 Schematic description of coating ALG on oil bodies. 

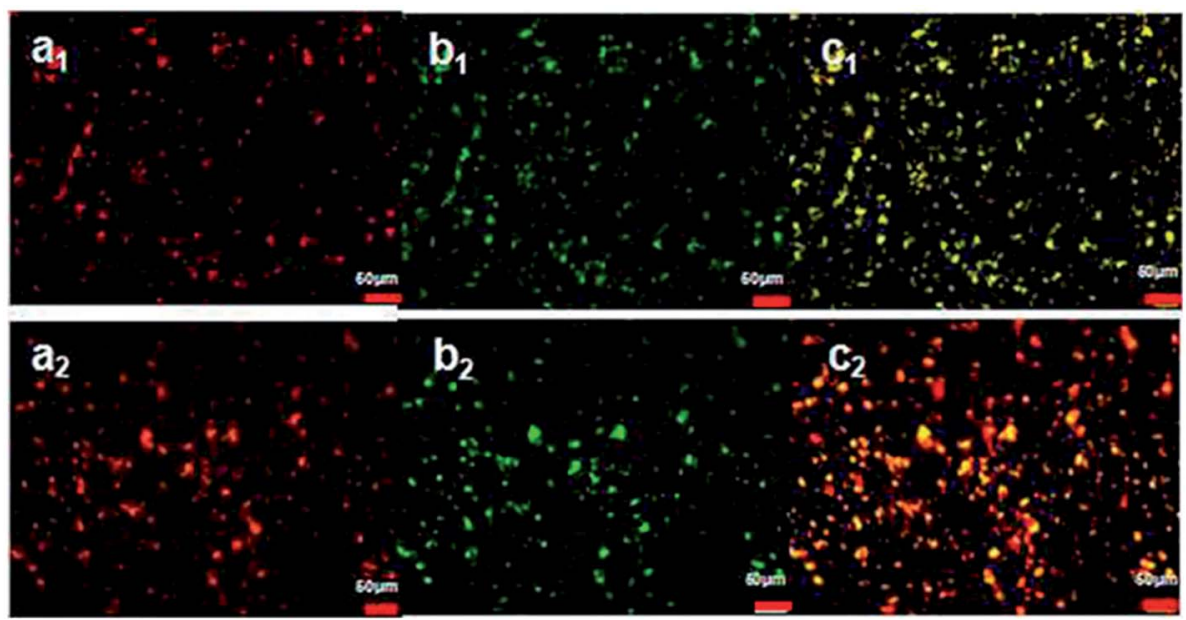

Fig. 4 Fluorescent micrographs of uncoated oil bodies ( 1 wt\% oil bodies, 0 wt\% ALG) $\left(a_{1}, b_{1}\right.$ and $c_{1}$ ) and oil bodies coated by ALG ( 1 wt\% oil bodies and $0.35 \mathrm{wt} \% \mathrm{ALG})\left(\mathrm{a}_{2}, \mathrm{~b}_{2}\right.$ and $\left.\mathrm{c}_{2}\right)$ : (a) is the fluorescent micrographs emitted at the wavelength of $538 \mathrm{~nm}$ when excited by blue laser of $488 \mathrm{~nm}$; (b) is the fluorescent micrographs emitted at the wavelength of $572 \mathrm{~nm}$ when exited by green laser of $543 \mathrm{~nm}$; (c) is the superposition of (a) and (b), respectively. The continuous phase of the emulsions is $50 \mathrm{mM}$ sodium phosphate and $\mathrm{pH}$ is 4.5 . Each scale bar represents $50 \mu \mathrm{m}$.

the uncoated OB emulsions, after the superposition, we can see that the uncoated oil bodies in the emulsions were yellow fluorescent as indicated in Fig. $4\left(c_{1}\right)$. In contrast, in Fig. $4\left(c_{2}\right)$, for the coated $\mathrm{OB}$ emulsions, oil body cores were yellow fluorescent, while the outer layers were red fluorescent, which were formed by the ALG molecules. These results demonstrate the location of the ALG adsorbed on the oil bodies, and further confirm that ALG coating increases the electrostatic and steric repulsion between the oil bodies, concurrently decreases the van der Waals attraction, thereby increasing their stability to aggregation.

\subsection{Influence of $\mathrm{pH}$ on the stabilities of oil body emulsions}

As shown in Fig. 5, at pH 4-5, the $\zeta$-potential of OB emulsions with ALG were negative and the absolute value was significantly higher than that of uncoated oil bodies (Fig. 5a). This difference can be attributed to the adsorption of anionic ALG molecules to the surfaces of the oil bodies and the neutralization of positive charge. The mean particle diameter of the uncoated OB emulsions increased significantly (Fig. 5b), large size aggregation appeared in the microscopic structure (Fig. 5c), and rapid creaming in the OB emulsions was observed with increasing $\mathrm{pH}$

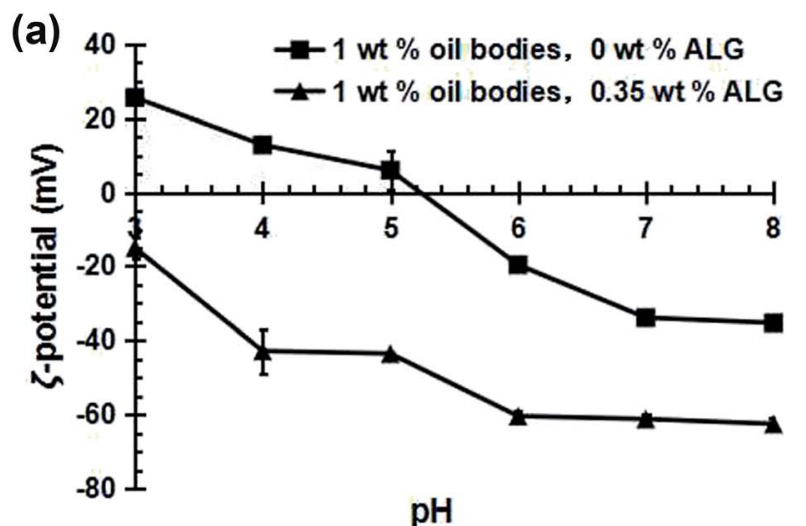

(c)

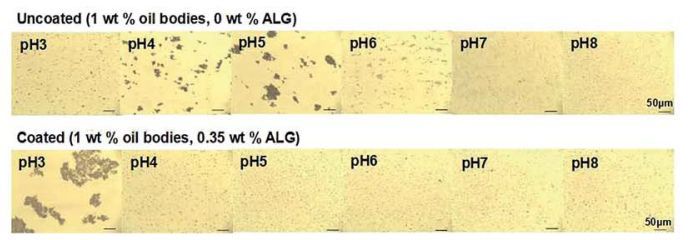

(b)

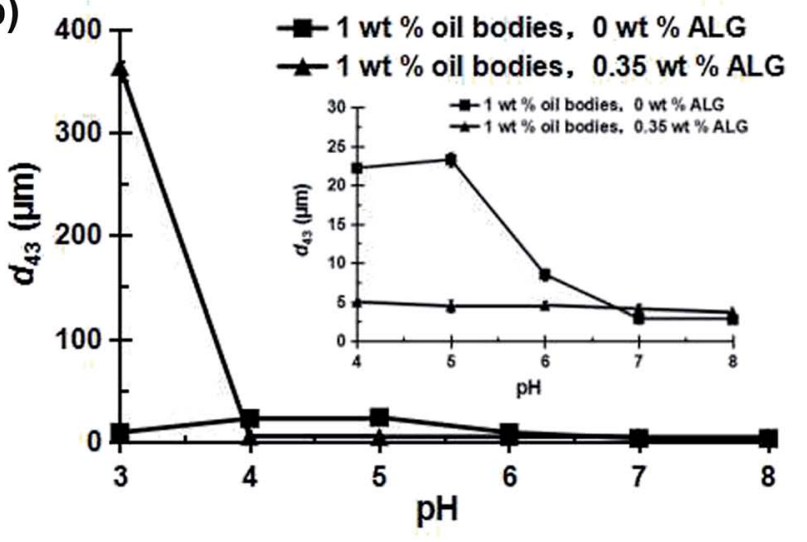

(d)

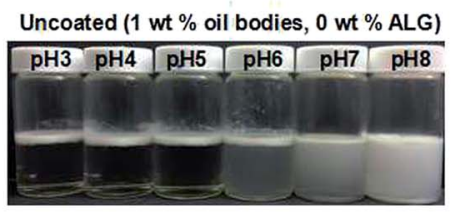

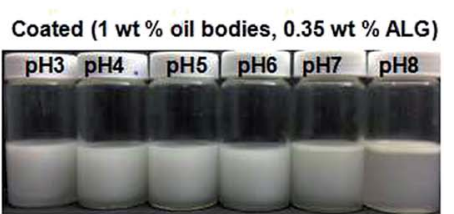

Fig. $5 \mathrm{pH}$ effect on $\zeta$-potential (a); mean particle diameter $\left(d_{43}\right)(b)$; the microscopic structure (c) and the creaming stability $(\mathrm{d})$ of uncoated ( $1 \mathrm{wt} \%$ oil bodies, $0 \mathrm{wt} \%$ ALG) and coated ( $1 \mathrm{wt} \%$ oil bodies, $0.35 \mathrm{wt} \%$ ALG) OB emulsions. The oil bodies were dispersed in $50 \mathrm{mM}$ sodium phosphate buffer solution. The creaming observation was made after storage at $22 \pm 2{ }^{\circ} \mathrm{C}$ for 7 days. 
(Fig. 5d). These were because that the electrostatic repulsive force between the oil bodies is weak when the $\mathrm{pH}$ is near the isoelectric point, which leads to the instability of the OB emulsions. ${ }^{29,35,36}$ But for coated OB emulsions, the mean particle diameter were relatively small (Fig. 5b), oil bodies were well dispersed (Fig. 5c), and there was no evidence of creaming instability after 7 days of storage (Fig. 5d). The relatively thick charged polysaccharide layers surrounding the oil bodies, which increase the electrostatic and steric repulsion between the oil bodies, concurrently decrease the van der Waals attraction.

At pH 3 and pH 6, the oil body emulsions were slightly stable, as the mean particle diameter was relatively small (Fig. 5b), and the microscopic structure was slightly aggregated (Fig. 5c), but the creaming was very obvious after 7 days of storage (Fig. 5d). This was probably because the energy barrier of the interaction potential versus droplet separation was not sufficiently high to prevent completely droplet aggregation (Fig. 5a). ${ }^{34}$ At $\mathrm{pH} 3$, the mean particle diameter of the coated OB emulsions increased dramatically (Fig. 5b), and the large size of the aggregation appeared in the microscopic structure (Fig. 5c), but there was no evidence of creaming instability after 7 days storage (Fig. $5 d$ ). It was reported that under the condition of strong acid and high temperature, the molecular chain of ALG breaks into G block, M block and GM block with different lengths. ${ }^{37,38}$ The solubility of these blocks is different under different $\mathrm{pH}$ conditions. At $\mathrm{pH} 3$, the $\mathrm{M}$ block and part of the GM block dissolved, G block will precipitate. Therefore, the mean particle diameter was increased dramatically. At pH 6, the mean particle diameter of the coated $\mathrm{OB}$ emulsions was relatively small (Fig. 5b), the dispersion of the oil bodies was better (Fig. 5c). There was no evidence of creaming instability after 7 days of storage (Fig. 5d).
The mean particle diameter of the uncoated OB emulsions, as shown in Fig. 5b and 6b, were relatively small at $\mathrm{pH} 7-8$, and the dispersion property was good with no evidence of creaming after 7 days of storage (Fig. 5d). These results can be attributed to the relatively strong electrostatic repulsion between the oil bodies that prevent their aggregation (Fig. 5a). ${ }^{34}$ The mean particle diameter of the coated OB emulsions was relatively small (Fig. 5b), and the dispersion of the oil bodies was better (Fig. 5d). However, at $\mathrm{pH}$ 8, creaming phenomenon was observed after 7 days storage. Wu et al. had reported the similar work about using carrageenan to stabilize oil bodies. ${ }^{21}$ However, at $\mathrm{pH} 7$, even the -carrageenan, which has a high charge density and a helical conformation, could not disperse the oil bodies well, resulting in large droplet sizes and aggregation due to depletion flocculation. ${ }^{21}$ It is obvious that our ALG can better stabilize and disperse oil bodies at $\mathrm{pH} 7$ at the optimized conditions, probably due to the higher charge density and configuration of ALG.

Overall, these results clearly show that coating the soybean oil bodies with ALG layer can greatly extend the range of $\mathrm{pH}$ values at which they remain stable to aggregation.

\subsection{Influence of ionic strength on the stabilities of oil body emulsions}

As shown in Fig. 6a, the absolute value of the $\zeta$-potential of uncoated $\mathrm{OB}$ emulsions decreased with the increase of $\mathrm{NaCl}$ concentration, changing from around $-45.5 \mathrm{mV}$ at a concentration of $0 \mathrm{mM} \mathrm{NaCl}$ to around $-38.9 \mathrm{mV}$ at a concentration of $250 \mathrm{mM} \mathrm{NaCl}$. This is probably due to the electrostatic screening effects of sodium ions. ${ }^{34}$ The $\zeta$-potential of the coated
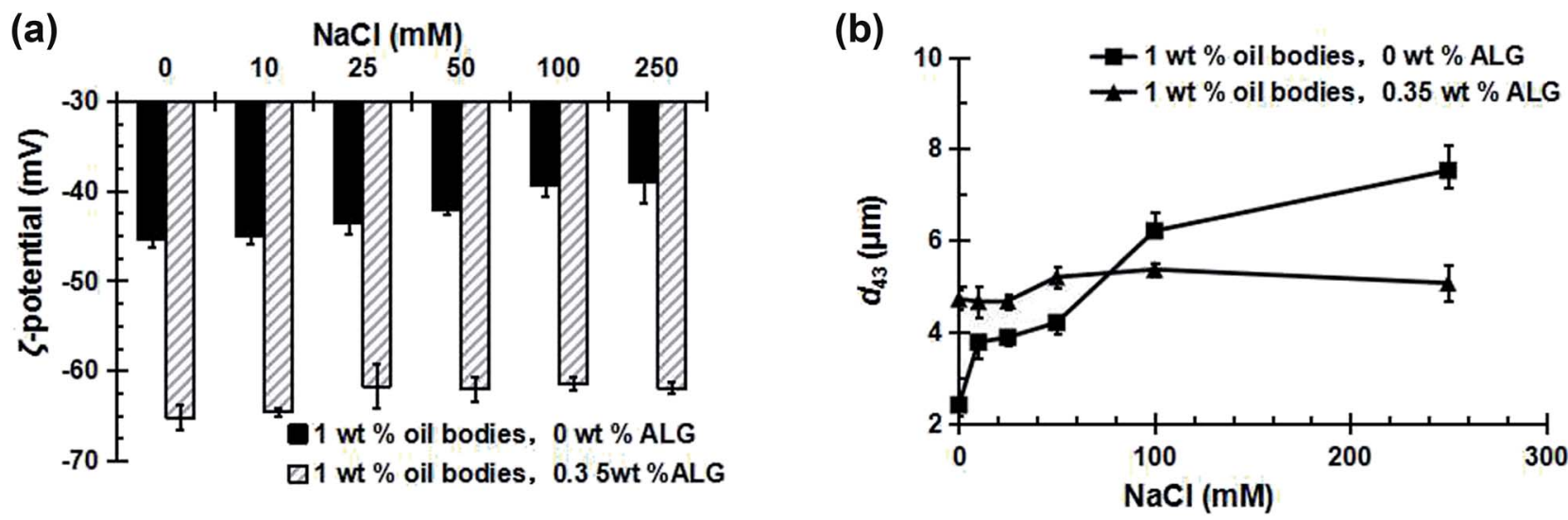

(c)
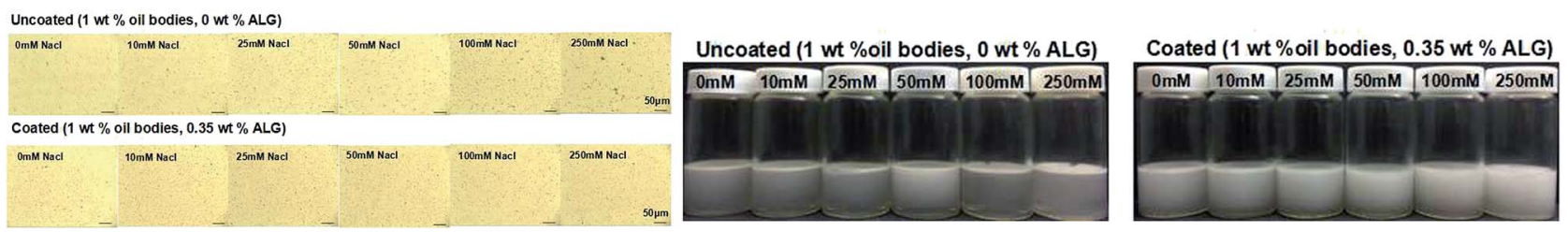

Fig. 6 Salt effect on $\zeta$-potential (a); mean particle diameter $\left(d_{43}\right)(b)$; the microscopic structure (c) and the creaming stability (d) of uncoated ( $1 \mathrm{wt} \%$ oil bodies, $0 \mathrm{wt} \% \mathrm{ALG}$ ) and coated ( $1 \mathrm{wt} \%$ oil bodies, $0.35 \mathrm{wt} \% \mathrm{ALG}$ ) OB emulsions at $\mathrm{pH} 7$. The oil bodies were dispersed in $50 \mathrm{mM}$ sodium phosphate buffer solution. The creaming observation was made after storage at $22 \pm 2{ }^{\circ} \mathrm{C}$ for 7 days. 
OB emulsions showed the same trend with the concentration of $\mathrm{NaCl}$, but was more negative than that of the uncoated $\mathrm{OB}$ emulsions due to the presence of the anionic ALG layer.

As shown in Fig. 6b, the mean particle diameter of uncoated $\mathrm{OB}$ emulsions increased with the increase of $\mathrm{NaCl}$ concentration. From the microscopic structure change in Fig. 6c, it means the aggregation phenomenon of the oil bodies becomes more and more serious. Creaming was also observed after 7 days storage as shown in Fig. 6d. These results can be attributed to the relatively low electrostatic repulsion between the oil bodies at this moment. This indicates that the presence of a small amount of $\mathrm{NaCl}$ will make the $\mathrm{OB}$ emulsions unstable to aggregation. However, the mean particle diameter of coated OB emulsions were almost unchanged at all salt concentrations examined, the microscopic structure is consistent with the mean particle diameter, and there was no evidence of creaming instability after 7 days storage.

These results show that the ALG coating greatly improves the salt stability of $\mathrm{OB}$ emulsions, which may have important implications for their utilization in food products.

\subsection{Influence of freeze-thaw cycling on the stabilities of oil body emulsions}

As shown in Fig. 7a, after three freeze-thaw cycles, the $\zeta$ potential of the uncoated oil bodies decreased slightly with increasing number of freeze-thaw cycles, from $-(45 \pm 1.4) \mathrm{mV}$ at zero cycles to $-(37 \pm 1.6) \mathrm{mV}$ after three cycles, which can be attributed to the large change in droplet size due to their
Table 1 Stability of different high OB concentration emulsions with different concentration of $\mathrm{ALG}^{a}$

\begin{tabular}{lllll}
\hline & \multicolumn{2}{c}{ OB (wt\%) } & & \\
\cline { 2 - 5 } ALG (wt\%) & 10 & 20 & 30 & 40 \\
\hline 0.2 & - & - & - & - \\
0.3 & - & - & - & - \\
0.4 & - & - & - & - \\
0.5 & + & - & - & - \\
0.6 & + & + & - & - \\
0.7 & + & + & - & - \\
0.8 & + & + & + & - \\
0.9 & + & + & + & + \\
1.0 & + & + & + & \\
$a$ “+” stable; “-” unstable. & & & &
\end{tabular}

coalescence after freezing. The $\zeta$-potential of the coated OB emulsions was changed only slightly with increasing number of freeze-thaw cycles, from $-(67.0 \pm 0.9) \mathrm{mV}$ at zero cycles to $-(69.4 \pm 1.2) \mathrm{mV}$ after three cycles. This was probably caused by the aggregations of oil bodies due to depletion flocculation in the presence of ALG.

From Fig. 7b-d, there was an increase in the mean particle diameter, and creaming instability of uncoated oil bodies after three freeze-thaw cycles. It can also be seen from the microscopic structure in Fig. 7c that the oil bodies coalesce into large oil droplets, which is consistent with the mean particle
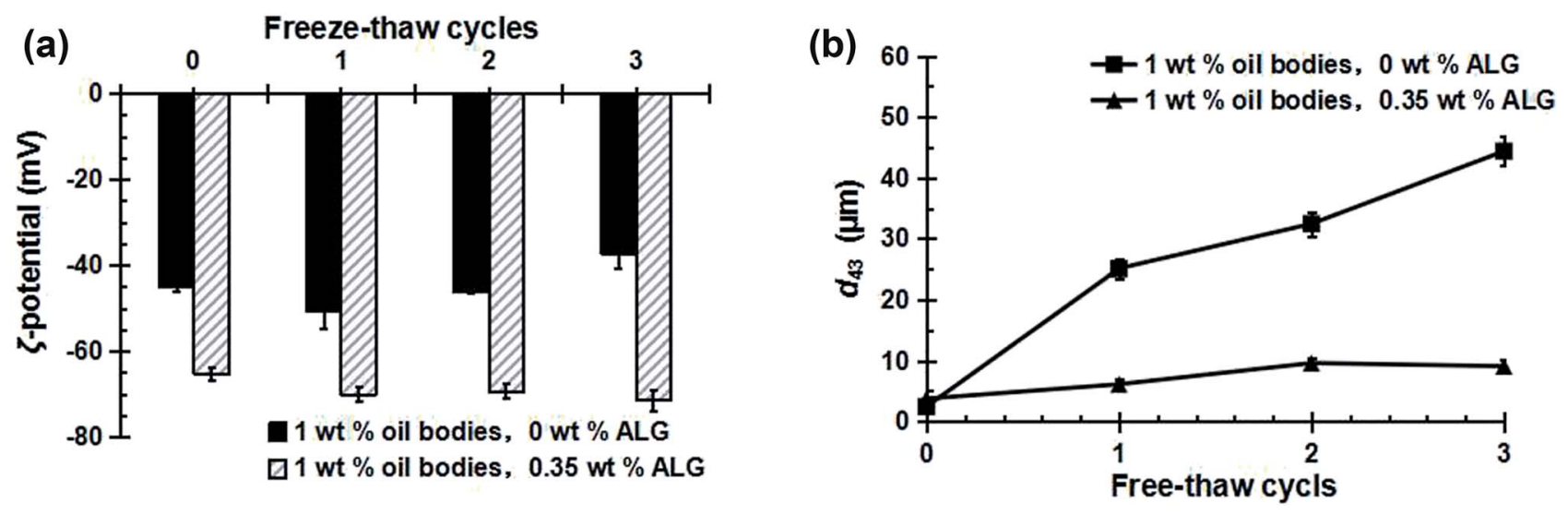

(c)

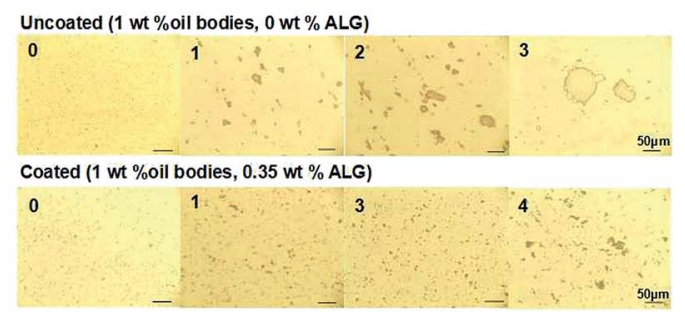

(d)

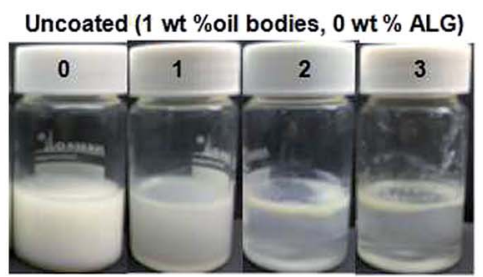

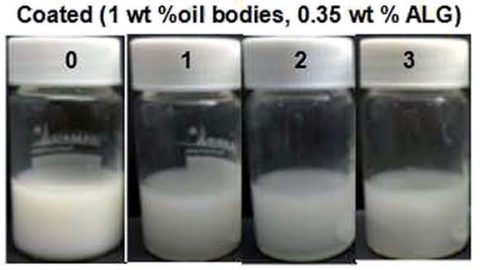

Fig. 7 Effect of freezing-thawing cycling on $\zeta$-potential (a); mean particle diameter $\left(d_{43}\right)(b)$; the microscopic structure (c) and the creaming stability (d) of uncoated ( $1 \mathrm{wt} \%$ oil bodies, 0 wt\% ALG) and coated ( $1 \mathrm{wt} \%$ oil bodies, $0.35 \mathrm{wt} \%$ ALG) OB emulsions at pH 7 . The oil bodies were dispersed in $50 \mathrm{mM}$ sodium phosphate buffer solution. The creaming observation was made after storage at $22 \pm 2{ }^{\circ} \mathrm{C}$ for 7 days." $0,1,2,3^{\prime \prime}$ represents the number of the freezing-thawing cycles. 
(a)

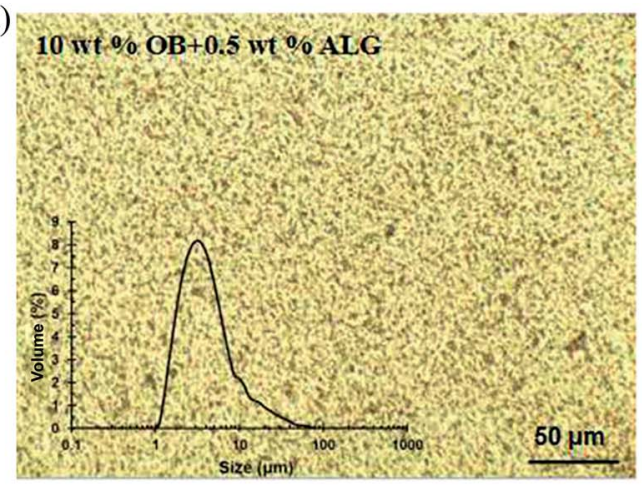

(c)

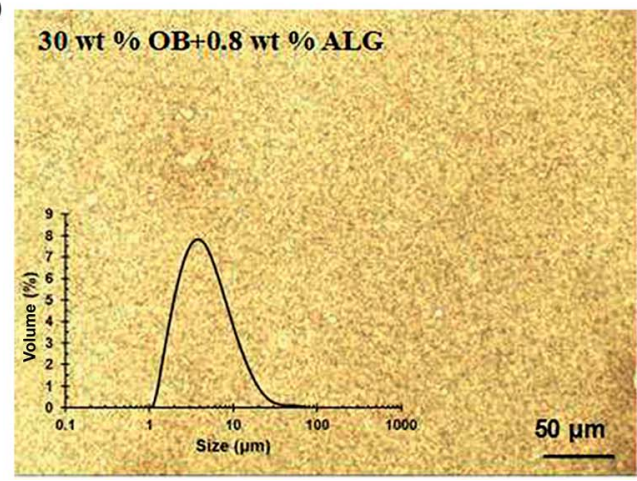

(b)

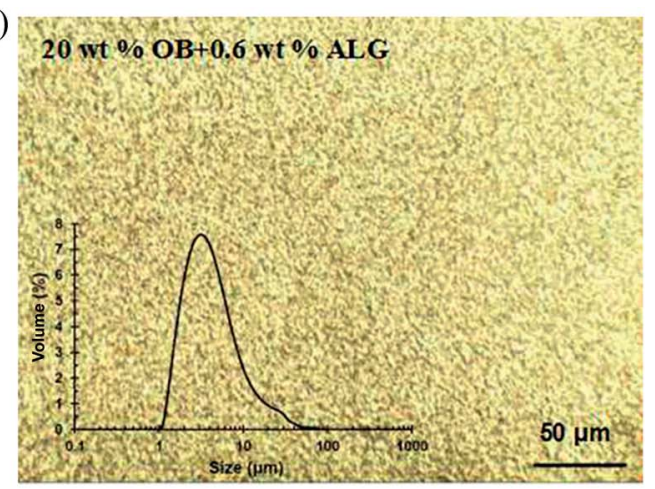

(d)

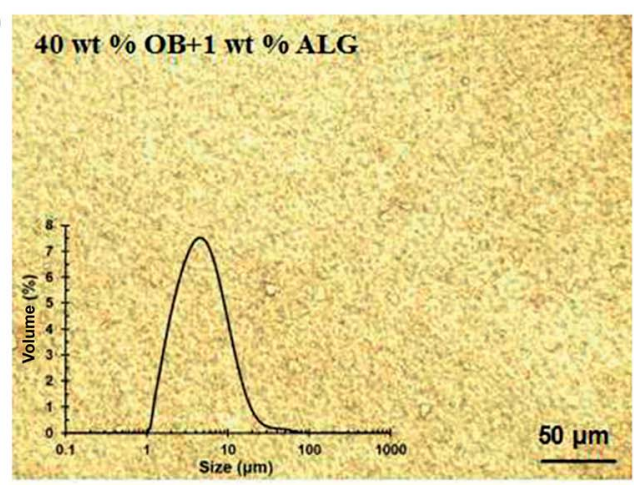

Fig. 8 Effect of ALG on the size distribution and microscopic structure of high concentration OB emulsions. The OB emulsion was prepared using $50 \mathrm{mM}$ sodium phosphate, and the $\mathrm{pH}$ is 4.5 .

diameter change and confirmed the observed changes in $\zeta$ potential. On the other hand, the mean particle diameter of the coated $\mathrm{OB}$ emulsions was slightly increased, the microscopic structure showed that only smaller aggregates appeared with the increase in the number of thermal cycles, and the creaming instability was not obvious. In previous studies, carrageenan alone cannot play a stabilizing role on the oil bodies at $\mathrm{pH} 3$ and at $\mathrm{pH} 7$ the carrageenan-coated oil bodies were stable after 3 cycles with the addition of sucrose, but not stable after fewer cycles. ${ }^{20}$ The ALG-stabilized oil bodies reported in our work are stable under thermal cycling all the time at $\mathrm{pH} 7$ with no need of addition of any sucrose.

These results indicate that the ALG coating protects the oil bodies during the freeze-thaw cycle and improves the stability of the $\mathrm{OB}$ emulsion.

\subsection{Stabilization of high concentration oil body emulsions by ALG}

In the real food emulsion products, a high concentration of oil phase is usually used. ${ }^{34}$ Therefore, the effect of ALG (0.2$1.0 \mathrm{wt} \%)$ on the properties of OB emulsions with high concentration $(10,20,30$, and $40 \mathrm{wt} \%)$ oil bodies was investigated in order to find the minimum amount of ALG needed to stabilize high concentration $\mathrm{OB}$ emulsions. By measuring the size distribution and microscopic structure of $\mathrm{OB}$ emulsions at $\mathrm{pH}$ 4.5 , the stability of different high concentration oil body emulsions with different concentration of ALG were shown in
Table 1. It indicates that the minimum concentrations of ALG required for stabilizing $\mathrm{OB}$ emulsions with concentration of 10 , 20,30 and $40 \%$ are $0.5,0.6,0.8$ and $1.0 \%$, respectively. The size distribution and microscopic structure of these OB emulsions with minimum ALG was presented in Fig. 8. The stability of the high concentration oil body emulsions against salt, $\mathrm{pH}$ and thermal-cycling was also improved by interacting with ALG (data was not shown here). The high concentration oil bodies stabilized with low concentration ALG in the emulsions, would provide more close to the practical application insights into further application of soybean oil bodies in food industry.

\section{Conclusions}

This study showed that ALG can be adsorbed to the surface of oil bodies by electrostatic interaction at $\mathrm{pH} 4.5$, with an optimal concentration of $0.35 \mathrm{wt} \%$ to stabilize $1 \mathrm{wt} \%$ OB emulsion. At pH 4-8, ALG-coated OB emulsions were more stable than the uncoated OB emulsions, indicating that ALG can greatly extend the range of $\mathrm{pH}$ values at which oil bodies remain stable to aggregation. Under different concentrations of $\mathrm{NaCl}$ and three freeze-thaw cycles, the ALG-coated OB emulsions were more stable than uncoated $\mathrm{OB}$ emulsions. With the increase of $\mathrm{NaCl}$ concentration and the number of freeze-thaw cycles, the uncoated soybean oil body emulsions were prone to droplet aggregation and creaming, but the ALG-coated OB emulsions were stable at all $\mathrm{NaCl}$ concentrations examined ( $\leqq 250 \mathrm{mM})$ and after all freeze-thaw cycles. Compared with previous 
studies on other polysaccharides, ALG-coated oil body emulsions showed better stabilities against aggregation and creaming under the conditions studied. These experiments clearly show that coating ALG layers on the soybean oil bodies has improved their emulsion stability to environmental conditions, including $\mathrm{pH}$, ionic strength and temperature, and can be utilized in the food product development. Finally, it was found that low concentrations of ALG can stabilize high concentration OB emulsions, which is more practical for the application of soybean oil bodies in food industry.

\section{Conflicts of interest}

There are no conflicts to declare.

\section{Acknowledgements}

The research was supported by the National Key Research and Development Program of China (No. 2017YFD0400200), and the National Natural Science Foundation of China (31571797, 31401649, 31601514). Nan Yang was also supported by China Scholarship Council (CSC 201708420099) and Hubei University of Technology (YXQN2016001).

\section{References}

1 A. H. C. Huang, Oil bodies and oleosins in seeds, Annu. Rev. Plant Physiol. Plant Mol. Biol., 1992, 43(4), 177-200.

2 K. Demetriades, J. N. Coupland and D. J. McClements, Role of lipid bodies and lipid-body proteins in seeds and other tissues, J. Plant Physiol., 2001, 158(4), 471-478.

3 D. J. Murphy and I. Cummins, Seed oil-bodies: isolation, composition and role of oil-body apolipoproteins, Phytochemistry, 1989, 28(8), 2063-2069.

4 J. T. C. Tzen, Y. Z. Cao, P. Laurent, C. Ratnayake and A. H. C. Huang, Lipids, proteins, and structure of seed oil bodies from diverse species, Plant Physiol., 1993, 101(1), 267-276.

5 D. J. Murphy, I. Hernández-Pinzón, K. Patel, R. G. Hope and J. McLauchlan, New insights into the mechanisms of lipidbody biogenesis in plants and other organisms, Biochem. Soc. Trans., 2000, 28(6), 710-711.

6 D. J. Murphy, I. Hernández-Pinzón and K. Patel, Role of lipid bodies and lipid-body proteins in seeds and other tissues, $J$. Plant Physiol., 2001, 158(4), 471-478.

7 J. T. C. Tzen, G. C. Lie and A. H. C. Huang, Characterization of the charged components and their topology on the surface of plant seed oil bodies, J. Biol. Chem., 1992, 267(22), 1562615634.

8 C. Peng, I. P. Lin, C. K. Lin and J. T. C. Tzen, Size and stability of reconstituted sesame oil bodies, Biotechnol. Prog., 2003, 19(5), 1623-1626.

9 M. C. M. Chen, C. L. Chyan, T. T. T. Lee, S. H. Huang and J. T. C. Tzen, Constitution of stable artificial oil bodies with triacylglycerol, phospholipid, and caleosin, J. Agric. Food Chem., 2004, 52(12), 3982-3987.
10 I. A. M. Appelqvist, M. Golding, R. Vreeker, and N. J. Zuidam, Emulsions as delivery systems in foods. in Encapsulation and Controlled Release Technologies in Food Systems, ed. J. M. Lakkis, Blackwell Publishing, Oxford, UK, 2007, pp. 41-81.

11 D. Iwanaga, D. A. Gray, I. D. Fisk, E. A. Decker, J. Weiss and D. J. McClements, Extraction and characterization of oil bodies from soy beans: a natural source of pre-emulsified soybean oil, J. Agric. Food Chem., 2007, 55(2), 8711-8716.

12 A. Benichou, A. Aserin, R. Lutz and N. Garti, Formation and characterization of amphiphilic conjugates of whey protein isolate (WPI)/xanthan to improve surface activity, Food Hydrocolloids, 2007, 21(3), 379-391.

13 B. Wang, L. J. Wang, D. Li, B. Adhikari and J. Shi, Effect of gum Arabic on stability of oil-in-water emulsion stabilized by flaxseed and soybean protein, Carbohydr. Polym., 2011, 86(1), 343-351.

14 E. Bouyer, G. Mekhloufi, I. L. Potier, T. D. F. D. Kerdaniel, J. L. Grossiord, V. Rosilio and F. Agnely, Stabilization mechanism of oil-in-water emulsions by $\beta$-lactoglobulin and gum arabic, J. Colloid Interface Sci., 2011, 354(2), 467477.

15 S. Hua, H. Z. Ma, X. Li, H. X. Yang and A. Q. Wang, pHsensitive sodium alginate/poly(vinyl alcohol) hydrogel beads prepared by combined $\mathrm{Ca}^{2+}$ crosslinking and freezethawing cycles for controlled release of diclofenac sodium, Int. J. Biol. Macromol., 2010, 46(5), 517-523.

16 M. Ionita, M. A. Pandele and H. Iovu, Sodium alginate/ graphene oxide composite films with enhanced thermal and mechanical properties, Carbohydr. Polym., 2013, 94(1), 339-344.

17 D. A. Rees and J. W. B. Samuel, The structure of alginate acid. Part VI. Minor features and structural variations, J. Chem. Soc. C, 1967, 22, 2295-2298.

18 S. A. Fioramonti, C. Arzeni, M. R. Pilosof, A. C. Rubiolo and L. G. Santiago, Influence of freezing temperature and maltodextrin concentration on stability of linseed oil-inwater multilayer emulsions, J. Food Eng., 2015, 156, 31-38.

19 S. A. Fioramonti, M. J. Martinez, M. R. Pilosof, A. C. Rubiolo and L. G. Santiago, Multilayer emulsions as a strategy for linseed oil microencapsulation: Effect of $\mathrm{pH}$ and alginate concentration, Food Hydrocolloids, 2015, 43, 8-17.

20 N. N. Wu, X. Huang, X. Q. Yang, J. Guo, E. L. Zheng, S. W. Yin, J. W. Zhu, J. R. Qi, X. T. He and J. B. Zhang, Stabilization of soybean oil body emulsions using t-carrageenan: effects of salt, thermal treatment and freeze-thaw cycling, Food Hydrocolloids, 2012, 28, 110-120.

21 N. N. Wu, X. Q. Yang, Z. Teng, S. W. Yin, J. H. Zhu and J. R. Qi, Stabilization of soybean oil body emulsions using $\kappa$, $\mathrm{l}, \lambda$-carrageenan at different $\mathrm{pH}$ values, Food Res. Int., 2011, 44(4), 1059-1068.

22 AOAC, Official methods of analysis of international, Arlington, VA, USA, Association of Official Analytical Chemists, 2000.

23 Y. S. Ying, L. P. Zhao, L. G. Kong, L. Z. Kong, X. Z. Kong, Y. F. Hua and Y. M. Chen, Solubilization of proteins in extracted oil bodies by SDS: a simple and efficient protein sample preparation method for Tricine-SDS-PAGE, Food Chem., 2015, 181, 179-185. 
24 U. K. Laemmli, Cleavage of structural proteins during assembly of head of bacteriophage-T4, Nature, 1970, 227(5259), 680-685.

25 B. L. Strand, Y. A. Mørch, T. Espevik and G. Skjåk-Bræk, Visualization of alginate-poly-L-lysine-alginate microcapsules by confocal laser scanning microscopy, Biotechnol. Bioeng., 2003, 82(4), 386-394.

26 E. M. Herman, Immunogold-localization and synthesis of an oil-body membrane protein in developing soybean seeds, Planta, 1987, 172(3), 336-345.

27 A. Kalinski, D. L. Melroy, R. S. Dwivedi and E. M. Herman, A soybean vacuolar protein (P34) related to thiol proteases is synthesized as a glycoprotein precursor during seed maturation, J. Biol. Chem., 1992, 267(17), 12068-12076.

28 Y. Chen and T. Ono, Simple extraction method of nonallergenic intact soybean oil bodies that are thermally stable in an aqueous medium, J. Agric. Food Chem., 2010, 58(12), 7402-7407.

29 K. Demetriades, J. N. Coupland and D. J. McClements, Physical properties of whey protein stabilized emulsions as related to $\mathrm{pH}$ and NaCl, J. Food Sci., 1997, 62(2), 342-347.

30 D. Guzey, H. J. Kim and D. J. McClements, Factors influencing the production of $\mathrm{o} / \mathrm{w}$ emulsions stabilized by $\beta$-lactoglobulin-pectin membranes, Food Hydrocolloids, 2004, 18(6), 967-975.

31 R. L. C. Chuang, J. C. F. Chen, J. Chu and J. T. C. Tzen, Characterization of seed oil bodies and their surface oleosin isoforms from rice embryos, J. Biochem., 1996, $120(1), 74-81$.

32 D. Guzey and D. J. McClements, Impact of electrostatic interactions on formation and stability of emulsions containing oil droplets coated by $\beta$-lactoglobulin-pectin complexes, J. Agric. Food Chem., 2007, 55(2), 475-485.

33 D. J. McClements, Theoretical analysis of factors affecting the formation and stability of multilayered colloidal dispersions, Langmuir, 2005, 21(21), 9777-9785.

34 D. J. McClements, Food Emulsions: Principles, Practice, and Techniques, CRC Press: Boca Raton, FL, 2nd edn, 2005.

35 Y. S. Gu, E. A. Decker and D. J. McClements, Influence of pH and carrageenan type on properties of $\beta$-lactoglobulin stabilized oil-in-water emulsions, Food Hydrocolloids, 2005, 19(1), 83-91.

36 D. Guzey and D. J. McClements, Formation, stability and properties of multilayer emulsions for application in the food industry, Adv. Colloid Interface Sci., 2006, 128-130, 227-248.

37 A. Haug, B. Larsen and O. Smidsrød, A study of the constitution of alginic acid by partial acid hydrolysis, Acta Chem. Scand., 1966, 20, 183-190.

38 A. Haug, B. Larsen and O. Smidsrød, Studies on the sequence of uronic acid residues in alginic acid, Acta Chem. Scand., 1967, 21, 691-704. 